\title{
Mineral Composition of Wheat Flour Consumed in Brazilian Cities
}

\author{
Rennan G. O. Araujo, ${ }^{a}$ Samuel M. Macedo, ${ }^{a}$ Maria das Graças A. Korn, ${ }^{a}$ \\ Maria Fernanda Pimentel, ${ }^{b}$ Roy E. Bruns ${ }^{c}$ and Sergio L. C. Ferreira ${ }^{*, a}$
}

\author{
${ }^{a}$ Universidade Federal da Bahia, Instituto de Química, Grupo de Pesquisa em Química Analítica, \\ 40170-290 Salvador-BA, Brazil \\ ${ }^{b}$ Universidade Federal de Pernambuco, Departamento de Engenharia Química, Av. Arthur de Sá, s/n, \\ Cidade Universitária, 50740-521 Recife-PE, Brazil
}

'Instituto de Química, Universidade Estadual de Campinas, CP 6154, 13083-970 Campinas-SP, Brazil

\begin{abstract}
Neste trabalho, foi avaliada a composição mineral da farinha de trigo consumida no Brasil. $\mathrm{Na}$ etapa de amostragem foram coletadas 54 amostras em 15 cidades, incluindo as principais cidades brasileiras como: São Paulo, Rio de Janeiro, Salvador, Porto Alegre, Recife e outras. Os elementos determinados foram: cálcio, cobre, magnésio, manganês, ferro, fósforo, potássio e zinco. As amostras foram digeridas usando acido nítrico e peróxido de hidrogênio em sistema aberto. A técnica analítica empregada foi a espectrometria de emissão óptica com plasma indutivamente acoplado (ICP OES). A validação do método (incluindo digestão e determinação) foi confirmada usando um material de referência certificado de farinha de trigo fornecido pelo National Institute of Standards \& Technology (NIST). Considerando as 54 amostras analisadas, os resultados demonstraram que os macronutrientes: cálcio, magnésio, potássio e fósforo encontram-se em média de 0,$27 ; 0,35 ; 1,71$ e $1,92 \mathrm{mg} \mathrm{g}^{-1}$, com variação da concentração de $0,11-1,96 ; 0,19-0,51$; 0,76-3,16 e 0,81-7,15 $\mathrm{mg} \mathrm{g}^{-1}$, respectivamente. Os micronutrientes: cobre, ferro, manganês e zinco encontram-se em média de 1,$84 ; 37,82 ; 8,25$ e $9,41 \mu \mathrm{g} \mathrm{g}^{-1}$, com a variação de concentração de $1,00-2,80 ; 10,46-146,58 ; 3,89-14,74$ e $5,07-13,93 \mu \mathrm{g} \mathrm{g}^{-1}$, respectivamente. Os resultados foram também avaliados usando as técnicas de análise multivariadas: análise de componente principal (PCA) e análise de agrupamento hierárquico (HCA).
\end{abstract}

In the present paper, the mineral composition of wheat flour consumed in Brazil was evaluated. In the sampling step 54 samples were collected in 15 cities, including principal Brazilian cities such as: São Paulo, Rio de Janeiro, Salvador, Porto Alegre, Recife and others. The elements determinate were: calcium, copper, magnesium, manganese, iron, phosphorus, potassium and zinc. The samples were digested using nitric acid and hydrogen peroxide in open system. The analytical technique employed was Inductively Coupled Plasma Optical Emission Spectrometry (ICP OES). The method validation (including digestion and determination) was performed using a certified reference material of wheat flour furnished by National Institute of Standards \& Technology (NIST). Considering the 54 samples analyzed, the results demonstrated that the macronutrients: calcium, magnesium, potassium and phosphorus have average contents of $0.27,0.35,1.71$ and $1.92 \mathrm{mg} \mathrm{g}^{-1}$, for concentration ranges of 0.11-1.96, 0.19-0.51, 0.76-3.16 and 0.81-7.15 $\mathrm{mg} \mathrm{g}^{-1}$, respectively. The micronutrients: copper, iron, manganese and zinc have average contents of 1.84, 37.8, 8.2 and $9.4 \mu \mathrm{g} \mathrm{g}^{-1}$, for concentration ranges of $1.00-2.80,10.5-146.6,3.9-14.7$ and $5.1-13.9 \mu \mathrm{g} \mathrm{g}^{-1}$, respectively. The results were also evaluated using the multivariate analysis techniques: principal component analysis (PCA) and hierarchical cluster analysis (HCA).

Keywords: wheat flour, minerals, Brazilian cities, ICP OES, principal component analysis (PCA), hierarchical cluster analysis (HCA)

\section{Introduction}

Wheat is one of the most consumed cereals of human foods. In the form of flour it is used for preparation of

*e-mail: slcf@ufba.br breads, cookies, pizzas, cakes and other bakery products. For this reason, several papers have been written on the characterization and nutritional evaluation of this cereal and its flour. ${ }^{1-10}$ Prabhasankar and Rao evaluated the lipid content and fatty acid composition in wheat flours. ${ }^{1} \mathrm{Yu}$ and co-workers compared the antioxidant 
properties of wheat flours grown at different locations. ${ }^{2}$ Another paper determined carotenoid, tocopherol, phenolic acid, and antioxidant properties of Maryland grown soft wheat. ${ }^{3}$ Siener and co-workers evaluated the oxalate content in several species of grain wheat. ${ }^{4}$ A recent paper determined the effects of genotype and growing environment on the phenolic contents and antioxidant activities of alcohol-soluble extracts from commercial wheat cultivars. ${ }^{5}$ Dupont et al. ${ }^{6}$ proposed a method of sequential extraction for determination of gliadins, glutenins and other proteins in wheat flour. The phytochemical compositions and antioxidant activities of bran samples of seven wheat varieties from four different countries were evaluated. Phenolic acid composition, tocopherol content, carotenoid profile, and total phenolic content were determined. ${ }^{7}$ Sorouraddin proposed a method using a chemiluminescence reaction for the determination of copper in wheat flour. ${ }^{8}$ Ferreira and co-workers proposed a method for the determination of manganese in wheat flour employing slurry sampling flame atomic absorption spectrometry. ${ }^{9}$ Sanz-Medel and co-workers performed a method for the total determination and quantitative speciation analysis of selenium in wheat flour using inductively coupled plasma mass spectrometry (ICP-MS). ${ }^{10}$

In the present paper, the mineral contents (calcium, copper, iron, magnesium, manganese, phosphorus, potassium and zinc) of wheat flour consumed in Brazil were evaluated. The data were processed using principal component analysis (PCA) and hierarchical cluster analysis (HCA) to test for homogeneity of the multiple analytical results as well as to identify outliers that should be removed from the data set in order to obtain representative values for Brazilian wheat flour. In the recent years PCA and HCA has been used for evaluation and characterization of data of foods as: cereal, ${ }^{11-13}$ honey, ${ }^{11-12}$ wine $^{16-20}$ and others. ${ }^{21-23}$

\section{Materials and Methods}

\section{Instrumentation}

An inductively coupled plasma optical emission spectrometer with an axially-viewed configuration (ICP OES, VISTA PRO, Varian, Mulgrave, Australia) was used for $\mathrm{Ca}, \mathrm{Cu}, \mathrm{Fe}, \mathrm{K}, \mathrm{Mg}, \mathrm{Mn}, \mathrm{P}$ and $\mathrm{Zn}$ determination. The system is equipped with a simultaneous CCD solid-state detector that allows measurements from 167 to $785 \mathrm{~nm}$. The pre-optical systems are purged with argon in order to enable readings below $180 \mathrm{~nm}$. The polychromator was thermostated at $34{ }^{\circ} \mathrm{C}$ and purged with argon. An end-on gas interface was used in the axially viewed configuration to minimize interferences caused by self-absorption and recombination, to provide a wide linear dynamic range and low background. The observation zone in the axially viewed system was automatically set by the program supplied with the Vista AX control software using the Mn II $257.610 \mathrm{~nm}$ emission line. The operational parameters are listed in Table 1. All emission signals were integrated using the automated adaptative integration time that is performed in VISTA equipments according to line intensities and analyte concentrations. All measurements were performed using two pixels for each wavelength. The sample introduction system employed was comprised of a concentric nebulizer and a cyclonic spray chamber. The wavelengths of the analytical lines were selected in most of the cases considering the most prominent line and, alternatively, secondary lines were used to prevent possible interferences. All analyses were performed in triplicate and checked by standard addition.

Table 1. Characteristics and instrumental parameters used in the axially viewed ICP OES

\begin{tabular}{|c|c|}
\hline \multicolumn{2}{|c|}{ ICP conditions } \\
\hline RF generator power/(W) & 1300 \\
\hline Plasma gas rate/(mL min $\left.{ }^{-1}\right)$ & 15.0 \\
\hline Auxiliary gas rate $/\left(\mathrm{mL} \mathrm{min}{ }^{-1}\right)$ & 1.5 \\
\hline Nebulizer gas rate/(mL/min) & 0.81 \\
\hline Sample uptake rate $/\left(\mathrm{mL} \min ^{-1}\right)$ & 0.8 \\
\hline Nebulizer type & Concentric, Sea Spray \\
\hline Spray chamber & Cyclone type \\
\hline Replicates & 3 \\
\hline Injector tube diameter/(mm) & 2.4 \\
\hline Signal integration time/(s) & $1 \mathrm{~s}$ \\
\hline \multicolumn{2}{|c|}{ Analysis wavelength/(nm) } \\
\hline Ca II 317.933 & $\mathrm{Cu}$ I 324.754 \\
\hline Fe II 238.204 & K I 766.467 \\
\hline Mg II 285.213 & Mn II 259.372 \\
\hline P I 213.613 & Zn II 202.548 \\
\hline
\end{tabular}

(I) line of atomic emission

(II) line of ionic emission

\section{Reagents and reference solutions}

All reagents were of analytical grade unless otherwise stated. Ultrapure water was obtained from an EASYpure RF (Barnstedt, Dubuque, IA, USA). Nitric acid and hydrogen peroxide were of Suprapur quality (Merck). Laboratory glassware was kept overnight in $10 \%$ nitric acid solution. The glassware was rinsed with deionized water before use and dried in a dust free environment. The commercially available metal standard solutions $\left(1.000 \pm 0.002 \mathrm{mg} \mathrm{L}^{-1}\right)$ (Titrisol Merck, Damstadt, Germany) were prepared for the 
standard working range. Analytical curves were obtained within 6.0 to $100.0 \mathrm{mg} \mathrm{L}^{-1}$ for calcium, magnesium, potassium and phosphorus and within 0.02 to $10.0 \mathrm{mg} \mathrm{L}^{-1}$ for manganese, zinc, copper and iron.

\section{Sample collection and storage}

During the period from May/2005 to February/2006, 54 wheat flour samples were collected in 15 Brazilian cities in diverse areas of Brazil. The cities were: Salvador (SSA), Feira de Santana (FSA), Jequié (JEQ), Belém (BEL), Macapá (MCP), Fortaleza (FTZ), Recife (REC), Aracaju (AJU), Rio de Janeiro (RIO), Niterói, (NIT), São Paulo (SSP), Poços de Caldas (PDC), Brasília (BSB), Porto Alegre (POA), Natal (RGN), Florianópolis (FLP) and São Bento (PAB).

\section{Humidity determination}

The humidity determinations of all the samples were determined by weight loss after drying in a flow-air oven at $40{ }^{\circ} \mathrm{C}$ for $20 \mathrm{~h}$ as recommended by the AOAC. ${ }^{24}$

\section{Sample digestion}

About $0.5 \mathrm{~g}$ of the wheat flour samples, $10.0 \mathrm{~mL}$ of concentrated nitric acid and $0.5 \mathrm{~mL}$ of hydrogen peroxide were placed in a glass vessel and heated on a hot plate. Later, the digested material was quantitatively transferred to $10 \mathrm{~mL}$ volumetric flasks and diluted with water.

\section{Accuracy of analytical method}

The accuracy of the method used for determination of the elements in wheat flour samples was confirmed by analysis of certified reference material, furnished by National Institute of Standard and Technology (Gaithersburg, MD, USA), wheat flour NIST 1567a. This material was also decomposed using nitric acid and hydrogen peroxide. The results obtained are described in Table 2.

Table 2. Results obtained for the certified reference materials analyzed $(n=3)$

\begin{tabular}{lcc}
\hline CRM $1567 \mathrm{a}$ & \multicolumn{2}{c}{ Wheat flour } \\
\hline Element & Certified value & Achieved value \\
Calcium $/(\%)$ & $0.0191 \pm 0.0004$ & $0.0188 \pm 0.0006$ \\
Magnesium/(\%) & $0.040 \pm 0.002$ & $0.0391 \pm 0.0018$ \\
Potassium $/(\%)$ & $0.133 \pm 0.003$ & $0.136 \pm 0.004$ \\
Phosphorus/(\%) & $0.134 \pm 0.006$ & $0.131 \pm 0.006$ \\
Zinc/ $\left(\mu \mathrm{g} \mathrm{g}^{-1}\right)$ & $11.6 \pm 0.4$ & $11.1 \pm 1.6$ \\
Copper/ $\left(\mu \mathrm{g} \mathrm{g}^{-1}\right)$ & $2.1 \pm 0.2$ & $2.1 \pm 0.1$ \\
Manganese $/\left(\mu \mathrm{g} \mathrm{g}^{-1}\right)$ & $9.4 \pm 0.9$ & $9.7 \pm 0.7$ \\
Iron/ $\left(\mu \mathrm{g} \mathrm{g}^{-1}\right)$ & $14.0 \pm 0.5$ & $14.1 \pm 1.3$ \\
\hline
\end{tabular}

\section{Multivariate analysis}

Principal component analysis (PCA) permits two and three dimensional graphical representations of higher order dimensional spaces. Here an eight dimensional space for which each mineral concentration is represented by a coordinate axis is projected onto two dimensional graphs so that the statistical distribution of the data can be visualized. The existence of samples belonging to different populations or of outliers that do not belong to any of these populations can be verified. Since statistical information is lost when eight dimensional space is projected onto two dimensional graphs a complementary hierarchical cluster analysis (HCA) was performed. This method exhibits its results in dendrograms that are determined from exact interpoint distances. Although dendrograms are not as easy to interpret as graphs no loss of statistical information occurs.

\section{Results and Discussion}

\section{Determination mineral content of wheat flour}

The results of the determinations of eight elements, calcium, magnesium, phosphorus, potassium, zinc, iron, copper and manganese, in 54 wheat flour samples are summarized in Table 3. These data are described as interval confidence at $95 \%$. In these can be observed that: phosphorus, potassium, magnesium and calcium show the highest levels of concentration. The average contents and the concentration ranges achieved are respectively: 1.92 and $0.89-7.15 \mathrm{mg} \mathrm{g}^{-1}$ for phosphorus, 1.71 and $0.76-3.16 \mathrm{mg} \mathrm{g}^{-1}$ for potassium, 0.35 and 0.19-0.51 for magnesium and 0.27 and $0.11-1.96 \mathrm{mg} \mathrm{g}^{-1}$ for calcium. The micronutrients: copper, iron, manganese and zinc have average contents of $1.84,37.8,8.2$ and $9.4 \mu \mathrm{g} \mathrm{g}^{-1}$, for concentration ranges of 1.00-2.80, 10.5-146.6, 3.9-14.7 and 5.1-13.9 $\mu \mathrm{g} \mathrm{g}^{-1}$, respectively.

\section{Data analysis}

The results of the determination of the elements in the 54 wheat flour samples were evaluated using two multivariate analysis techniques: principal component analysis (PCA) and hierarchical cluster analysis (HCA). A data matrix was constructed using the determined elements as columns and the wheat flour samples as rows.

Principal components analysis was performed on autoscaled data. The loadings of original variables on the first three principal components and the variances explained by each component are given in Table 4 . The first three principal components were chosen for modeling the data 
Table 3. Wheat flour samples*

\begin{tabular}{|c|c|c|c|c|c|c|c|c|}
\hline Sample & $\mathrm{Ca} /\left(\mu \mathrm{g} \mathrm{g}^{-1}\right)$ & $\mathrm{Cu} /\left(\mu \mathrm{g} \mathrm{g}^{-1}\right)$ & $\mathrm{Fe} /\left(\mu \mathrm{g} \mathrm{g}^{-1}\right)$ & $\mathrm{K} /\left(\mathrm{mg} \mathrm{g}^{-1}\right)$ & $\mathrm{Mg} /\left(\mathrm{mg} \mathrm{g}^{-1}\right)$ & $\mathrm{Mn} /\left(\mu \mathrm{g} \mathrm{g}^{-1}\right)$ & $\mathrm{P} /\left(\mathrm{mg} \mathrm{g}^{-1}\right)$ & $\mathrm{Zn} /\left(\mu \mathrm{g} \mathrm{g}^{-1}\right)$ \\
\hline AJU1 & $148.9 \pm 4.4$ & $1.54 \pm 0.04$ & $30.3 \pm 2.1$ & $1.808 \pm 0.024$ & $0.310 \pm 0.027$ & $4.7 \pm 0.2$ & $1.150 \pm 0.038$ & $7.0 \pm 0.4$ \\
\hline BEL1 & $138 \pm 15$ & $2.33 \pm 0.05$ & $28.0 \pm 1.8$ & $1.502 \pm 0.091$ & $0.332 \pm 0.016$ & $7.6 \pm 0.2$ & $1.096 \pm 0.031$ & $8.8 \pm 0.1$ \\
\hline BEL2 & $169.1 \pm 2.4$ & $2.03 \pm 0.04$ & $88.6 \pm 1.5$ & $1.785 \pm 0.091$ & $0.388 \pm 0.018$ & $8.9 \pm 0.6$ & $1.339 \pm 0.068$ & $8.3 \pm 0.6$ \\
\hline BSB1 & $212 \pm 22$ & $2.30 \pm 0.18$ & $22.3 \pm 2.1$ & $2.058 \pm 0.047$ & $0.442 \pm 0.006$ & $7.4 \pm 0.4$ & $1.382 \pm 0.019$ & $12.4 \pm 0.8$ \\
\hline BSB2 & $209 \pm 22$ & $2.26 \pm 0.14$ & $31.1 \pm 2.7$ & $1.80 \pm 0.22$ & $0.429 \pm 0.039$ & $8.7 \pm 1.3$ & $1.37 \pm 0.11$ & $13.9 \pm 1.7$ \\
\hline BSB3 & $183.2 \pm 6.7$ & $2.54 \pm 0.18$ & $31.9 \pm 0.2$ & $1.836 \pm 0.024$ & $0.413 \pm 0.030$ & $11.1 \pm 0.6$ & $1.450 \pm 0.099$ & $9.5 \pm 1.0$ \\
\hline BSB4 & $178 \pm 19$ & $2.80 \pm 0.24$ & $32.6 \pm 0.6$ & $1.78 \pm 0.20$ & $0.372 \pm 0.018$ & $14.7 \pm 1.8$ & $1.34 \pm 0.14$ & $11.5 \pm 0.3$ \\
\hline FLP1 & $158 \pm 11$ & $1.54 \pm 0.12$ & $46.6 \pm 4.5$ & $1.386 \pm 0.070$ & $0.386 \pm 0.027$ & $8.4 \pm 0.6$ & $1.17 \pm 0.12$ & $9.1 \pm 0.7$ \\
\hline FLP2 & $139.5 \pm 8.7$ & $1.44 \pm 0.07$ & $54.4 \pm 4.6$ & $1.172 \pm 0.051$ & $0.285 \pm 0.011$ & $5.4 \pm 0.2$ & $0.911 \pm 0.045$ & $6.3 \pm 0.4$ \\
\hline FLP3 & $174 \pm 10$ & $1.17 \pm 0.12$ & $52.9 \pm 1.7$ & $1.73 \pm 0.19$ & $0.346 \pm 0.035$ & $6.0 \pm 0.4$ & $1.165 \pm 0.097$ & $7.5 \pm 0.7$ \\
\hline FSA1 & $172.8 \pm 7.2$ & $2.02 \pm 0.03$ & $31.4 \pm 0.5$ & $2.595 \pm 0.066$ & $0.401 \pm 0.013$ & $9.6 \pm 0.7$ & $1.151 \pm 0.038$ & $11.8 \pm 1.2$ \\
\hline FSA2 & $184.7 \pm 3.1$ & $2.40 \pm 0.23$ & $20.6 \pm 2.4$ & $2.44 \pm 0.14$ & $0.395 \pm 0.033$ & $12.0 \pm 0.8$ & $1.100 \pm 0.066$ & $13.6 \pm 0.6$ \\
\hline FSA3 & $196.1 \pm 6.0$ & $1.64 \pm 0.15$ & $18.9 \pm 1.8$ & $2.57 \pm 0.12$ & $0.365 \pm 0.040$ & $6.5 \pm 0.1$ & $1.082 \pm 0.083$ & $9.2 \pm 0.4$ \\
\hline FSA4 & $199 \pm 14$ & $1.69 \pm 0.14$ & $26.7 \pm 2.9$ & $2.609 \pm 0.038$ & $0.343 \pm 0.012$ & $7.0 \pm 0.2$ & $1.136 \pm 0.032$ & $12.4 \pm 1.3$ \\
\hline FTZ1 & $147.2 \pm 3.6$ & $2.04 \pm 0.05$ & $13.4 \pm 0.7$ & $1.610 \pm 0.015$ & $0.367 \pm 0.005$ & $9.0 \pm 0.6$ & $1.372 \pm 0.063$ & $10.1 \pm 0.5$ \\
\hline FTZ2 & $158.0 \pm 0.4$ & $1.46 \pm 0.04$ & $32.4 \pm 2.0$ & $1.614 \pm 0.070$ & $0.258 \pm 0.011$ & $5.7 \pm 0.4$ & $1.108 \pm 0.065$ & $6.6 \pm 0.7$ \\
\hline JEQ1 & $160 \pm 19$ & $1.69 \pm 0.04$ & $29.1 \pm 2.0$ & $1.699 \pm 0.078$ & $0.286 \pm 0.013$ & $8.9 \pm 1.0$ & $1.080 \pm 0.036$ & $8.4 \pm 0.5$ \\
\hline JEQ2 & $213 \pm 10$ & $2.56 \pm 0.18$ & $30.3 \pm 2.9$ & $2.29 \pm 0.18$ & $0.511 \pm 0.048$ & $14.6 \pm 1.2$ & $1.58 \pm 0.10$ & $13.8 \pm 1.0$ \\
\hline JEQ3 & $137 \pm 11$ & $1.47 \pm 0.04$ & $24.8 \pm 2.6$ & $1.352 \pm 0.042$ & $0.194 \pm 0.006$ & $4.9 \pm 0.1$ & $0.896 \pm 0.057$ & $6.3 \pm 0.5$ \\
\hline JEQ4 & $542 \pm 57$ & $1.99 \pm 0.23$ & $35.9 \pm 2.8$ & $2.70 \pm 0.21$ & $0.376 \pm 0.027$ & $9.5 \pm 0.4$ & $6.22 \pm 0.50$ & $9.0 \pm 0.2$ \\
\hline MCP1 & $134 \pm 12$ & $2.29 \pm 0.15$ & $45.7 \pm 3.8$ & $0.757 \pm 0.014$ & $0.312 \pm 0.036$ & $9.2 \pm 0.1$ & $1.197 \pm 0.061$ & $8.0 \pm 0.8$ \\
\hline MCP2 & $112.3 \pm 8.1$ & $2.46 \pm 0.23$ & $36.2 \pm 2.9$ & $0.812 \pm 0.081$ & $0.361 \pm 0.042$ & $9.8 \pm 0.5$ & $1.312 \pm 0.097$ & $9.1 \pm 0.5$ \\
\hline NIT1 & $117.5 \pm 8.2$ & $1.66 \pm 0.08$ & $23.6 \pm 0.7$ & $0.868 \pm 0.072$ & $0.277 \pm 0.028$ & $6.5 \pm 0.5$ & $1.090 \pm 0.092$ & $7.7 \pm 0.2$ \\
\hline NIT2 & $174 \pm 13$ & $1.68 \pm 0.07$ & $20.7 \pm 2.3$ & $0.962 \pm 0.043$ & $0.332 \pm 0.030$ & $6.7 \pm 0.4$ & $1.245 \pm 0.076$ & $8.0 \pm 0.6$ \\
\hline NIT3 & $185.2 \pm 6.9$ & $2.35 \pm 0.18$ & $39.7 \pm 1.2$ & $1.000 \pm 0.018$ & $0.356 \pm 0.013$ & $7.4 \pm 0.2$ & $1.310 \pm 0.042$ & $9.0 \pm 0.2$ \\
\hline NIT4 & $158 \pm 13$ & $1.57 \pm 0.04$ & $13.9 \pm 1.3$ & $0.903 \pm 0.004$ & $0.308 \pm 0.036$ & $6.2 \pm 0.1$ & $1.191 \pm 0.058$ & $6.5 \pm 0.8$ \\
\hline NIT5 & $166.1 \pm 5.4$ & $2.22 \pm 0.14$ & $11.8 \pm 1.8$ & $0.813 \pm 0.021$ & $0.345 \pm 0.016$ & $11.0 \pm 0.4$ & $1.157 \pm 0.088$ & $12.6 \pm 1.3$ \\
\hline NIT6 & $144 \pm 17$ & $1.40 \pm 0.02$ & $30.7 \pm 1.4$ & $0.903 \pm 0.035$ & $0.303 \pm 0.016$ & $6.1 \pm 0.2$ & $1.17 \pm 0.14$ & $7.3 \pm 0.9$ \\
\hline NIT7 & $521 \pm 55$ & $1.59 \pm 0.08$ & $50.8 \pm 4.5$ & $1.53 \pm 0.13$ & $0.390 \pm 0.013$ & $8.9 \pm 0.4$ & $7.15 \pm 0.46$ & $10.0 \pm 1.2$ \\
\hline $\mathrm{PAB} 1$ & $468 \pm 25$ & $2.39 \pm 0.08$ & $40.8 \pm 1.3$ & $1.364 \pm 0.027$ & $0.366 \pm 0.004$ & $11.5 \pm 0.2$ & $5.94 \pm 0.30$ & $12.0 \pm 0.5$ \\
\hline PDC1 & $160 \pm 17$ & $2.00 \pm 0.05$ & $34.2 \pm 1.4$ & $1.81 \pm 0.13$ & $0.341 \pm 0.040$ & $11.9 \pm 1.1$ & $0.992 \pm 0.034$ & $11.8 \pm 1.9$ \\
\hline PDC2 & $167 \pm 14$ & $2.00 \pm 0.01$ & $20.1 \pm 0.7$ & $1.725 \pm 0.066$ & $0.312 \pm 0.016$ & $8.4 \pm 0.8$ & $1.040 \pm 0.001$ & $8.7 \pm 1.9$ \\
\hline PDC3 & $147 \pm 13$ & $1.56 \pm 0.08$ & $37.9 \pm 3.4$ & $1.48 \pm 0.12$ & $0.188 \pm 0.017$ & $4.1 \pm 0.1$ & $0.810 \pm 0.021$ & $6.4 \pm 0.1$ \\
\hline POA1 & $177.7 \pm 4.5$ & $1.87 \pm 0.08$ & $44.3 \pm 3.1$ & $1.68 \pm 0.12$ & $0.407 \pm 0.028$ & $9.9 \pm 0.6$ & $1.332 \pm 0.044$ & $10.9 \pm 0.8$ \\
\hline POA2 & $180.4 \pm 9.1$ & $1.34 \pm 0.11$ & $143.1 \pm 7.1$ & $1.477 \pm 0.093$ & $0.310 \pm 0.015$ & $7.0 \pm 0.3$ & $1.065 \pm 0.042$ & $10.1 \pm 1.0$ \\
\hline POA3 & $162 \pm 19$ & $1.36 \pm 0.10$ & $146.6 \pm 15.2$ & $1.44 \pm 0.14$ & $0.286 \pm 0.013$ & $6.4 \pm 0.4$ & $1.051 \pm 0.074$ & $7.7 \pm 0.5$ \\
\hline REC1 & $232 \pm 22$ & $1.77 \pm 0.07$ & $42.7 \pm 4.7$ & $1.686 \pm 0.033$ & $0.336 \pm 17.33$ & $7.5 \pm 0.3$ & $1.246 \pm 0.092$ & $8.1 \pm 0.6$ \\
\hline REC2 & $554 \pm 23$ & $1.83 \pm 0.02$ & $21.2 \pm 2.0$ & $2.879 \pm 0.11$ & $0.388 \pm 0.078$ & $9.2 \pm 0.3$ & $6.23 \pm 0.09$ & $9.5 \pm 0.6$ \\
\hline RGN1 & $1958 \pm 165$ & $1.35 \pm 0.11$ & $37.2 \pm 3.6$ & $1.035 \pm 0.029$ & $0.198 \pm 0.080$ & $4.2 \pm 0.1$ & $5.34 \pm 0.34$ & $5.1 \pm 0.5$ \\
\hline RIO1 & $787 \pm 72$ & $1.98 \pm 0.11$ & $12.6 \pm 0.1$ & $3.16 \pm 0.37$ & $0.491 \pm 0.049$ & $9.3 \pm 0.8$ & $7.11 \pm 0.88$ & $13.0 \pm 1.1$ \\
\hline $\mathrm{RIO} 2$ & $193 \pm 16$ & $1.88 \pm 0.18$ & $47.3 \pm 4.0$ & $1.73 \pm 0.18$ & $0.360 \pm 0.039$ & $7.3 \pm 0.6$ & $1.24 \pm 0.13$ & $9.5 \pm 0.2$ \\
\hline RIO3 & $132.0 \pm 5.8$ & $1.89 \pm 0.18$ & $29.0 \pm 2.4$ & $0.885 \pm 0.006$ & $0.324 \pm 0.028$ & $7.0 \pm 0.1$ & $1.176 \pm 0.065$ & $9.1 \pm 0.3$ \\
\hline RIO4 & $604 \pm 63$ & $1.63 \pm 0.06$ & $26.6 \pm 2.1$ & $2.622 \pm 0.075$ & $0.316 \pm 0.031$ & $7.2 \pm 0.2$ & $5.67 \pm 0.08$ & $7.2 \pm 0.5$ \\
\hline SSA1 & $293 \pm 24$ & $1.17 \pm 0.12$ & $10.46 \pm 1.2$ & $2.05 \pm 0.12$ & $0.399 \pm 0.018$ & $5.8 \pm 0.3$ & $1.268 \pm 0.039$ & $10.2 \pm 1.0$ \\
\hline SSA2 & $248 \pm 27$ & $1.67 \pm 0.12$ & $77.5 \pm 7.2$ & $1.711 \pm 0.042$ & $0.435 \pm 0.014$ & $9.1 \pm 0.1$ & $1.345 \pm 0.025$ & $11.2 \pm 0.8$ \\
\hline SSA3 & $298.4 \pm 2.2$ & $1.25 \pm 0.07$ & $83.4 \pm 7.6$ & $1.855 \pm 0.098$ & $0.341 \pm 0.019$ & $7.9 \pm 0.5$ & $1.148 \pm 0.085$ & $9.7 \pm 0.7$ \\
\hline SSA4 & $250 \pm 30$ & $1.25 \pm 0.04$ & $41.1 \pm 4.7$ & $1.80 \pm 0.13$ & $0.327 \pm 0.007$ & $7.5 \pm 0.1$ & $1.082 \pm 0.068$ & $8.9 \pm 0.7$ \\
\hline SSA5 & $230 \pm 22$ & $1.00 \pm 0.05$ & $36.9 \pm 4.4$ & $1.596 \pm 0.034$ & $0.246 \pm 0.007$ & $3.9 \pm 0.2$ & $0.918 \pm 0.011$ & $7.5 \pm 0.3$ \\
\hline SSA6 & $1001.0 \pm 9.4$ & $1.04 \pm 0.05$ & $40.0 \pm 0.1$ & $2.230 \pm 0.078$ & $0.240 \pm 0.006$ & $4.3 \pm 0.1$ & $4.96 \pm 0.30$ & $7.0 \pm 0.2$ \\
\hline SSP1 & $146.1 \pm 5.1$ & $1.89 \pm 0.23$ & $10.8 \pm 1.1$ & $2.308 \pm 0.044$ & $0.366 \pm 0.026$ & $7.6 \pm 0.7$ & $1.09 \pm 0.12$ & $6.4 \pm 0.1$ \\
\hline SSP2 & $127.2 \pm 0.6$ & $2.42 \pm 0.14$ & $22.6 \pm 2.4$ & $2.01 \pm 0.10$ & $0.432 \pm 0.052$ & $11.4 \pm 0.3$ & $1.308 \pm 0.037$ & $12.0 \pm 0.9$ \\
\hline SSP3 & $148.8 \pm 7.0$ & $2.65 \pm 0.29$ & $18.5 \pm 1.4$ & $2.18 \pm 0.10$ & $0.437 \pm 0.031$ & $13.5 \pm 1.1$ & $1.152 \pm 0.033$ & $12.9 \pm 1.5$ \\
\hline SSP4 & $107.5 \pm 3.0$ & $1.70 \pm 0.11$ & $21.6 \pm 1.5$ & $1.257 .48 \pm 0.050$ & $0.323 \pm 0.034$ & $9.9 \pm 0.6$ & $1.179 \pm 0.038$ & $8.7 \pm 0.8$ \\
\hline SSP5 & $149 \pm 12$ & $1.90 \pm 0.18$ & $32.8 \pm 1.9$ & $1.63 \pm 0.10$ & $0.332 \pm 0.017$ & $7.8 \pm 0.5$ & $1.27 \pm 0.14$ & $8.3 \pm 0.8$ \\
\hline
\end{tabular}

* Average of three determinations \pm interval confidence at $95 \%$. 
since they describe almost $80 \%$ of the total variance. The remaining variance most likely represents noise since their corresponding principal components do not have significant variable loadings. Note that the first three principal components have important loadings for all eight variables so they are all included in the model. Manganese, copper, zinc and magnesium are the dominant variables for the first principal component (PC1) and represents $42.26 \%$ of the total variance, while calcium, iron, potassium and phosphorus show very low values. The distribution of the samples throughout PC1 is relatively uniform, showing that the concentrations of these metals have continuous distributions for all the flours. The second principal component (PC2) explains $24.07 \%$ of the total variance. Examining its loadings, one observes that phosphorus and calcium are the most dominant variables with smaller contributions from potassium. Finally the third principal component (PC3) explains $12.37 \%$ of the total variance and is essentially described by the iron concentration.

Figure 1 shows the projection of the first two PCs that describes $66.33 \%$ of the total data variance. Two clusters of points can be observed. The upper cluster with high scores on the second PC is densely populated whereas the lower one contains only eight points. Since the second PC has large negative loadings for calcium and phosphorus the samples represented by points in the lower cluster are expected to have high concentrations of these elements. Whereas the calcium concentrations for samples of the upper cluster range from 0.11 to $0.29 \mathrm{mg} \mathrm{g}^{-1}$ those of the lower group are much higher, between 0.47 to $1.96 \mathrm{mg} \mathrm{g}^{-1}$. Phosphorus concentrations are
Table 4. Loadings of the variables for the three first PC's (principal components)

\begin{tabular}{lccc}
\hline & PC1 & PC2 & PC3 \\
\hline $\mathrm{Ca}$ & 0.2354 & -0.8562 & -0.0422 \\
$\mathrm{Cu}$ & -0.8189 & 0.1783 & -0.2383 \\
$\mathrm{Fe}$ & 02754 & 0.1441 & 0.9111 \\
$\mathrm{~K}$ & -0.4456 & -0.5515 & 0.1793 \\
$\mathrm{Mg}$ & -0.8850 & -0.0760 & 0.1851 \\
$\mathrm{Mn}$ & -0.8948 & 0.0841 & 0.0331 \\
$\mathrm{P}$ & -0.0755 & -0.9073 & 0.0159 \\
$\mathrm{Zn}$ & -0.8892 & -0.0018 & 0.1817 \\
total variance $(\%)$ & 42.26 & 24.07 & 12.37 \\
cumulative variance $(\%)$ & 42.26 & 66.33 & 78.70 \\
\hline
\end{tabular}

much lower for samples with points in the upper cluster, 0.81 to $1.58 \mathrm{mg} \mathrm{g}^{-1}$ than for those in the lower one, 4.6 to $7.15 \mathrm{mg} \mathrm{g}^{-1}$. On the other hand the first PC does not discriminate between these two groups of points. As such there are no significant differences in the concentrations of copper, magnesium, manganese and zinc for samples of these two groups, since all have large negative loadings on this PC

The samples in the lower cluster are PAB1, RIO1, RIO4, JEQ4, REC2, NIT7, SSA6 e RGN1. As such one can expect significantly higher calcium and phosphorus concentrations for these samples.

Figure 2 contains the score graph for the first and third PCs. Five samples, BEL2, POA2, POA3, SSA2 and SSA3 are well separated from the main cluster with scores of the third PC neatly discriminating these samples from the rest. Since the third PC is essentially the same as the iron

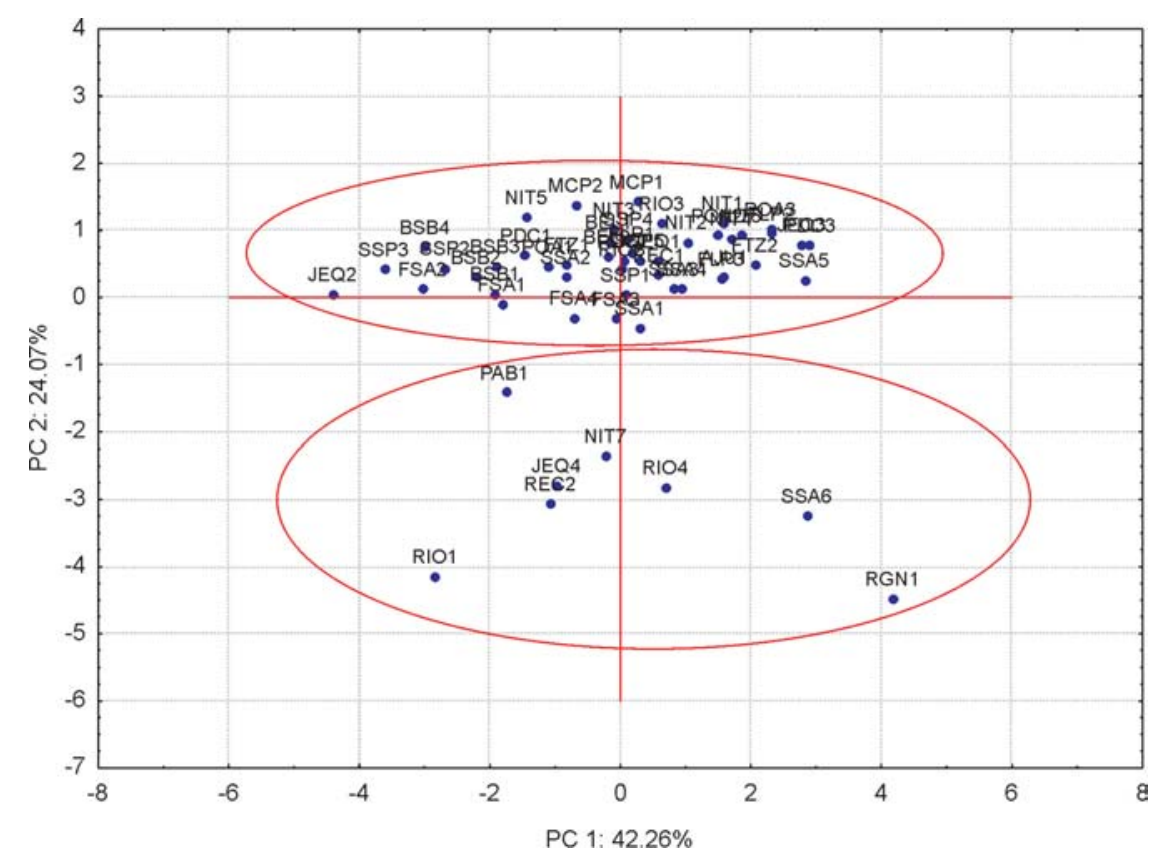

Figure 1. Plot of the first principal component (PC1) versus the second principal component (PC2). 
concentration and the BEL2, POA2, POA3, SSA2 and SSA3 samples have high scores on it these samples should be richer in iron than the other samples. This is indeed the case. Whereas these five samples have iron concentrations of 77.5 and $146.1 \mu \mathrm{g} \mathrm{g}^{-1}$ the rest of the samples have iron concentrations ranging from 10.5 to $54.4 \mu \mathrm{g} \mathrm{g}^{-1}$.

Hierarchical cluster analysis was applied to the autoscaled data using the single linkage method with Euclidean distances to calculate the sample interpoint distances and similarities. A hierarchical agglomerative procedure was employed to establish clusters. The results obtained are shown as a dendrogram in Figure 3, which shows the distinct formation of two clusters. For distances between 1400-3500 (half the distance scale on the ordinate) only two clusters exist, i.e. in this large distance interval there are only two vertical lines. This shows that the two groups in the two dimensional projection in Figure 1 are even more separated in eight dimensional real space since dendrograms are based on real distances between samples whereas principal component separations are projections.

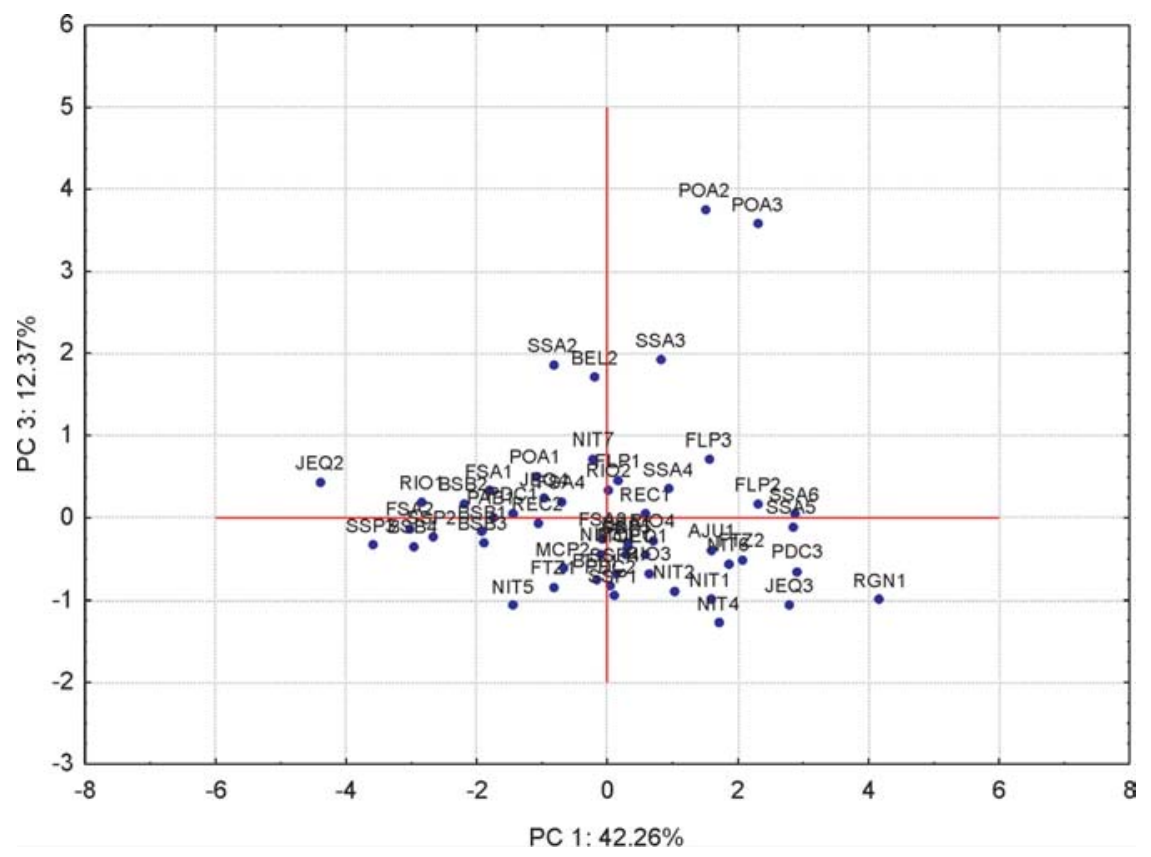

Figure 2. Principal components analysis $(\mathrm{PC} 1 \times \mathrm{PC} 3)$.

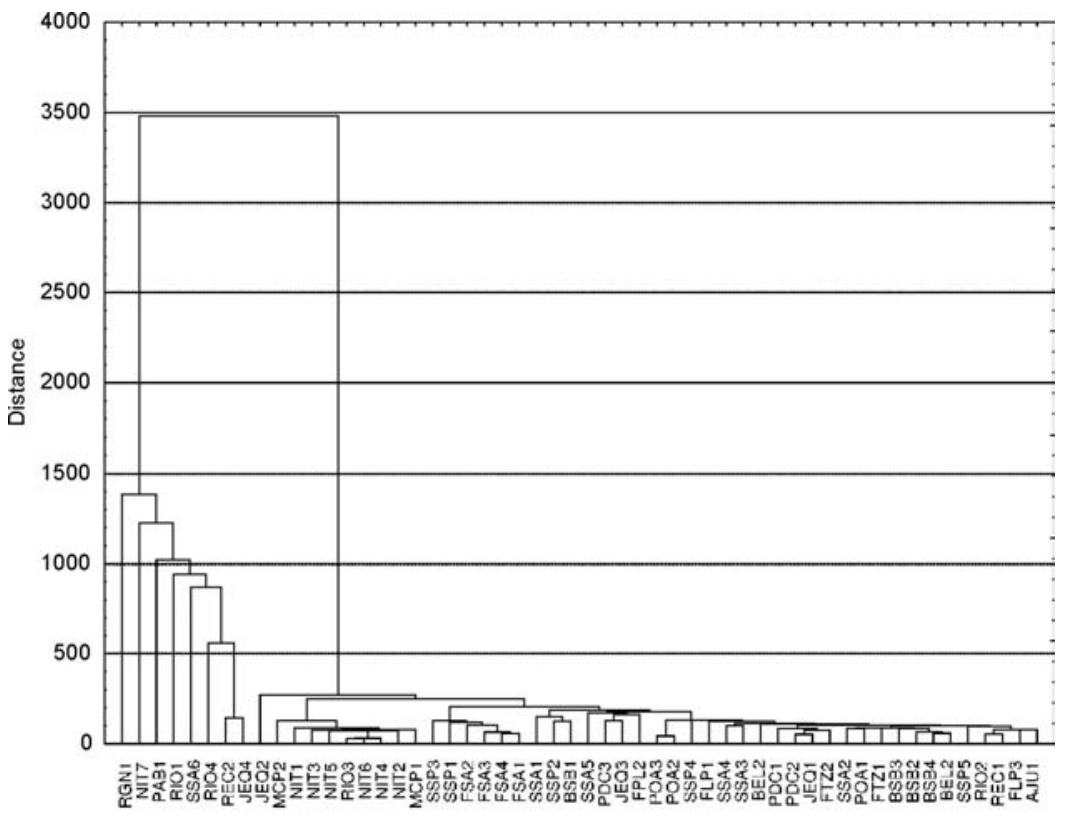

Figure 3. Dendogram for wheat flour: single linkage with Euclidean distances. 
One of the clusters has the same eight samples as found in the lower cluster in Figure 1 while the other has the rest of the samples. On the other hand the dendrogram is not able to discriminate the POA2 and POA3 outliers. This can be understood since these samples are only outliers along the third principal component that has only half the variance of the second principal component.

Table 5 contains the average, median and standard deviations of the concentrations of all eight elements in each of the three groups, regular flour, treated flour and the outliers. The elements that have high loadings on the first $\mathrm{PC}, \mathrm{Cu}, \mathrm{Mg}, \mathrm{Mn}$ and $\mathrm{Zn}$, have essentially the same concentrations in regular flour, treated flour and the outliers. So the first PC, that is an approximate average of the concentrations of these elements, measures sample to sample variations in concentrations that are relatively constant in these three sample groups. The second PC has its most important loadings from $\mathrm{Ca}, \mathrm{P}$ and $\mathrm{K}$. These elements have concentrations that are very high in the treated flour and much smaller but about the same in the regular flour and the outliers. Although there are only eight samples of treated flour the differences in $\mathrm{Ca}, \mathrm{P}$ and $\mathrm{K}$ concentrations are very large relative to the other samples and this PC describes more than half the variance of the first one. Finally the third PC has its only important loading from $\mathrm{Fe}$ and is measuring variations owing to high $\mathrm{Fe}$ contents in the outliers but low and very similar Fe contents in the regular and treated flour. The very high negative loadings of $\mathrm{Cu}, \mathrm{Mg}, \mathrm{Mn}$ and $\mathrm{Zn}$ on

Table 5. Mean, median and standard deviations for the eight elements

\begin{tabular}{|c|c|c|c|c|c|c|c|c|}
\hline & $\begin{array}{c}\mathrm{Ca} / \\
\left(\mu \mathrm{g} \mathrm{g}^{-1}\right)\end{array}$ & $\begin{array}{c}\mathrm{Cu} / \\
\left(\mu \mathrm{g} \mathrm{g}^{-1}\right)\end{array}$ & $\begin{array}{c}\mathrm{Fe} / \\
\left(\mu \mathrm{g} \mathrm{g}^{-1}\right)\end{array}$ & $\begin{array}{c}\mathrm{K} / \\
\left(\mathrm{mg} \mathrm{g}^{-1}\right)\end{array}$ & $\begin{array}{c}\mathrm{Mg} / \\
\left(\mathrm{mg} \mathrm{g}^{-1}\right)\end{array}$ & $\begin{array}{c}\mathrm{Mn} / \\
\left(\mu \mathrm{g} \mathrm{g}^{-1}\right)\end{array}$ & $\begin{array}{c}\mathrm{P} / \\
\left(\mathrm{mg} \mathrm{g}^{-1}\right)\end{array}$ & $\begin{array}{c}\mathrm{Zn} / \\
\left(\mu \mathrm{g} \mathrm{g}^{-1}\right)\end{array}$ \\
\hline \multicolumn{9}{|l|}{ Flour } \\
\hline Mean & 170.4 & 1.9 & 30.0 & 1.622 & 0.346 & 8.3 & 1.179 & 9.5 \\
\hline Median & 163.2 & 1.9 & 30.3 & 1.682 & 0.344 & 7.6 & 1.167 & 9.0 \\
\hline Std. Dev. & 38.7 & 0.4 & 11.3 & 0.531 & 0.065 & 2.6 & 0.157 & 2.3 \\
\hline \multicolumn{9}{|l|}{ Treated } \\
\hline Mean & 804.4 & 1.7 & 33.1 & 2.189 & 0.346 & 8.0 & 6.077 & 9.1 \\
\hline Median & 578.7 & 1.7 & 36.5 & 2.426 & 0.371 & 9.0 & 6.077 & 9.3 \\
\hline Std. Dev. & 497.9 & 0.4 & 12.2 & 0.785 & 0.091 & 2.6 & 0.779 & 2.6 \\
\hline \multicolumn{9}{|l|}{ Outliers } \\
\hline Mean & 211.6 & 1.5 & 107.8 & 1.653 & 0.352 & 7.8 & 1.190 & 9.4 \\
\hline Median & 180.4 & 1.4 & 88.6 & 1.711 & 0.341 & 7.9 & 1.148 & 9.7 \\
\hline Std. Dev. & 59.4 & 0.3 & 34.0 & 0.187 & 0.060 & 1.2 & 0.144 & 1.4 \\
\hline
\end{tabular}

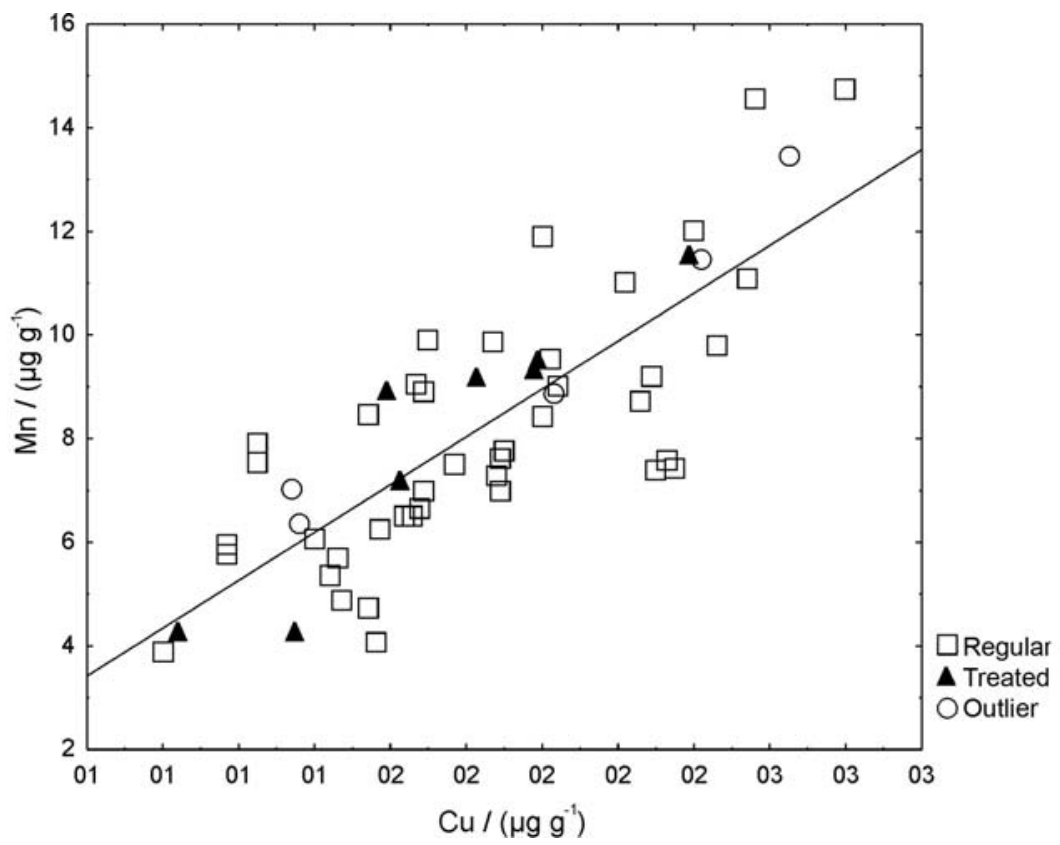

Figure 4. Graph of the Mn concentrations versus the $\mathrm{Cu}$ concentrations $(\mathrm{r}=0.80)$ for all the flour samples. 
the first PC indicate these variables have high correlations with one another. This is indeed true. All possible pairs of these elements have correlations between 0.6 and 0.8 . Figure 4 shows a graph of the $\mathrm{Mn}$ vs. $\mathrm{Cu}$ concentrations for all the flour samples for which the correlation coefficient is 0.8. These correlations seem to be intrinsic to all the flour samples whether they are treated or not.

\section{Conclusions}

Considering the analyzed data, the PCA and HCA models were efficient for the classification of the wheat flour samples, providing useful information on the similarity between the samples. The mineral composition and pattern recognition analysis of the 54 wheat flour samples in Brazilian cities showed three groups of samples. One group totaling 41 samples has a unique uniform distribution without the appearance of new trends or groupings. The second one formed by 8 samples that have high calcium and phosphorus concentrations, is the group with fermented samples. The third group has five samples with high iron concentrations.

\section{Acknowledgments}

The authors are grateful to Fundação de Amparo à Pesquisa do Estado da Bahia (FAPESB), Conselho Nacional de Desenvolvimento Científico e Tecnológico (CNPq) and Coordenação de Aperfeiçoamento de Pessoal de Nível Superior (CAPES)-PROCAD, for providing grants, and fellowships and for financial support.

\section{References}

1. Prabhasankar, P.; Rao, P. H.; J. Cereal Sci. 1999, 30, 315.

2. Yu, L. L.; Haley, S.; Perret, J.; Harris, M.; Food Chem. 2004, $86,11$.

3. Moore, J.; Hao, Z. G.; Zhou, K. Q.; Luther, M.; Costa, J.; Yu, L. L.; J. Agric. Food Chem. 2005, 53, 6649.

4. Siener, R.; Honow, R.; Voss, S.; Seidler, A.; Hesse, A.; J. Agric. Food Chem. 2006, 54, 3008.

5. Mpofu, A.; Sapirstein, H. D.; Beta, T.; J. Agric. Food Chem. 2006, 54, 1265 .

6. Dupont, F. M.; Chan, R.; Lopez, R., Wenzel, W. H.; J. Agric. Food Chem. 2005, 53, 1575.
7. Zhou, K., Su, L.; Yu, L. L.; J. Agric. Food Chem. 2004, 52, 6108.

8. Sorouraddin, M. H.; Manzoori, J. L.; Iranifam, M.; Talanta 2005, 66, 1117.

9. Araujo, R. G. O.; Dias, F. de S.; Macedo, S. M.; dos Santos, W. N. L., Ferreira, S. L.C.; Food Chem. 2007, 101, 397.

10. Huerta, V. D.; Reyes, L. H.; Marchante-Gayon, J. M.; Sanchez, M. L. F.; Sanz-Medel, A.; J. Anal. At. Spectrom. 2003, 18, 1243.

11. Sohn, M.; Himmelsbach, D. S.; Kays, S. E.; Archibald, D. D.; Barton, F. E.; Cereal Chem., 2005, 82, 660.

12. Karoui, R.; Cartaud, G.; Dufour, E.; J. Agric. Food Chem. 2006, 54, 2027.

13. Cocchi, M. G.; Foca, Lucisano, M.; Marchetti, A. ; Pagani, M. A.; Tassi, L.; Ulrici, A.; J. Agric. Food Chem. 2004, 52, 1062.

14. Ruoff, K.; Karoui, R.; Dufour, E.; Luginbuhl, W.; Bosset, J. O.; Bogdanov, S.; Amado, R.; J. Agric. Food Chem. 2005, 53, 1343.

15. Fernandez-Torres, R.; Perez-Bernal, J. L.; Bello-Lopez, M. A.; Callejon-Mochon, M.; Jimenez-Sanchez, J. C.; Guiraum-Perez, A.; Talanta 2005, 65, 686.

16. Boselli, E.; Minardi, M.; Giomo, A.; Frega, N. G.; Anal. Chim. Acta 2006, 563, 93.

17. Terrab, A.; Hernanz, D.; Heredia, F. J.; J. Agric. Food Chem. 2004, 52, 3441.

18. Camara, J. S.; Alves, M. A.; Marques, J. C.; Talanta 2006, 68, 1512.

19. Nikfardjam, M. S. P.; Mark, L.; Avar, P.; Figler, M.; Ohmacht, R.; Food Chem. 2006, 98, 453.

20. Boselli, E.; Boulton, R. B.; Thorngate, J. H.; Frega, N. G.; J. Agric. Food Chem. 2004, 52, 3843.

21. Andersen, K. E.; Bjergegaard, C.; Moller, P.; Sorensen, J. C.; Sorensen, H.;, J. Agric. Food Chem. 2005, 53, 5809.

22. Sousa, E. T.; Rodrigues, F. D.; Martins, C. C.; de Oliveira, F. S.; Pereira, P. A. D.; de Andrade, J. B.; Microchem. J., 2006, $82,142$.

23. Sola-Larranaga, C.; Navarro-Blasco, I.; Anal. Chim. Acta 2006, 555,354

24. http://www.codexalimentarius.net/download/standards/50/CXS acessed in April, 2007.

Received: August 18, 2007 Web Release Date: April 25, 2008

FAPESP helped in meeting the publication costs of this article. 